\title{
Simple evaluation of the degradation state of cultural heritage based on multi-view stereo
}

\author{
Nobuaki Kuchitsu", Masayuki Morii ${ }^{1}$, Shuji Sakai ${ }^{2}$ and Hiroki Unten²
}

\begin{abstract}
In this study, degradation of cultural heritage is discussed based on the comparison between the present shape of the Wareishi Rock Cliff Sculpture and its replica made 30 years ago through simple three-dimensional measurement using a multi-view stereo. The Wareishi Rock Cliff Sculpture, an important cultural property of Hiroshima Prefecture, is located near a shoreline. Local people often highlight that the sculpture seems to have recently been suffering from rapid degradation because of the direct impact of tidal ebb and flow. The present three-dimensional shape of this sculpture was investigated through multi-view stereo technique to accurately estimate the current degradation state. The same investigation was performed on the replica of the sculpture made in 1986 using a mold and exhibited in the Hiroshima Prefectural History Museum. The difference between the present shape of the sculpture and that of the replica revealed through the above investigation can be regarded as degradation of the sculpture that has occurred over the previous 30 years. The result is as follows. The difference was detected mainly on the middle part of the sculpture, which is a beltshaped portion parallel to the sea surface that is $\sim 20 \mathrm{~cm}$ high. The total area where more than $3 \mathrm{~mm}$ of displacement was detected constitutes $\sim 0.56 \%$ of the whole measured area. Accordingly, the degradation of the Wareishi Rock Cliff Sculpture does not seem to be recently accelerated but seems to be progressing at a regular pace since it was carved, especially in relation to the sea level rise. If the degradation extends up to the face of the sculpture in the future, some countermeasures may be required. The method used in this study will contribute to the conservation of cultural heritage through evaluating the degradation state of the heritage precisely and to the study of weathering by detecting longterm weathering.
\end{abstract}

Keywords: Wareishi Rock Cliff Sculpture, Sea level change, Replica, Hiroshima Prefectural History Museum, Sagi Island

\section{Introduction}

\section{Research background}

Heritage is our legacy from the past, what we live with today, and what we pass on to future generations (UNESCO World Heritage Centre 2005). In addition, as the Japan Consortium for International Cooperation in Cultural Heritage (2013) underlines, cultural heritage is a testament that has been created over humankind's long history. The protection and management of cultural heritage are means of ensuring their maximum possible vitality, values, and functions to the benefit of current and future generations (Szmelter 2013). Conservation of

\footnotetext{
* Correspondence: kuchitsu@tobunken.go.jp

'Tokyo National Research Institute for Cultural Properties, 13-43 Ueno Park,

Taito-ku, Tokyo 110-8713, Japan

Full list of author information is available at the end of the article
}

cultural heritage is often compared with human healthcare (Smith and Prrikryl 2007). In such an analogy, degraded cultural heritage is compared with a sick person. To prevent cultural heritage from further degradation, diagnosis of the present heritage condition is given priority to perform any conservation treatment or restoration work. It is similar to the case that no medical treatments are provided to a patient before a precise medical check. The causes of the degradation should further be revealed based on the present condition like identification of the disease. Finally, countermeasures can be discussed by considering how to remove the revealed causes in a manner similar to the extraction of the cause of a disease. As basic medical studies are indispensable for human healthcare, studies on precise description and weathering are needed for conservation of cultural heritage. 

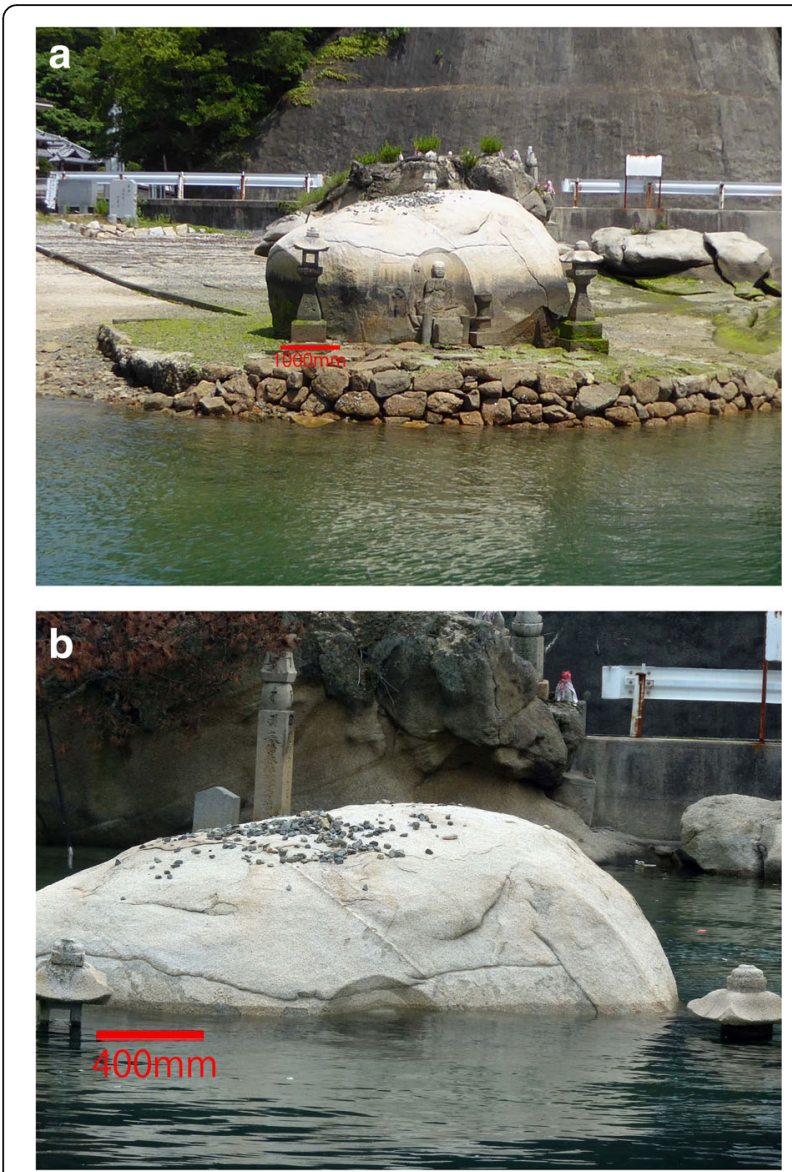

Fig. 1 The Wareishi Rock Cliff Sculpture. a During low tide (2016) and b during high tide of a spring tide (2012). The sculpture was carved on a granitic core stone and appears above the sea level during low tide. The lower mass of the core stone below the chest of the sculpture is covered with dark-colored materials. The whole sculpture sinks below the sea level during high tide of a spring tide

Stone weathering has been investigated on several stone monuments from such a viewpoint (Doehne and Price 2010). Among them, studies on the on-going weathering rate are especially effective to evaluate the present condition of stone monuments (Winkler 1986), for example, to ascertain whether the target monument requires an immediate measure to stop weathering or continuous prudent monitoring for a while. To understand the present weathering condition of target monuments, the first step would be to measure the precise shape of the stone surfaces.

Contact and non-contact methods have been practiced to measure the surface change rate of stones (Moses et al. 2014). Although contact methods, such as with micro-erosion meter, have been practiced on quite a few objects (Stephenson and Finlayson 2009), a non-contact and non-destructive method is generally preferred for avoiding value reduction of the cultural heritage. The non-destructive laser scanning measurement technique is often applied to describe the present surface condition

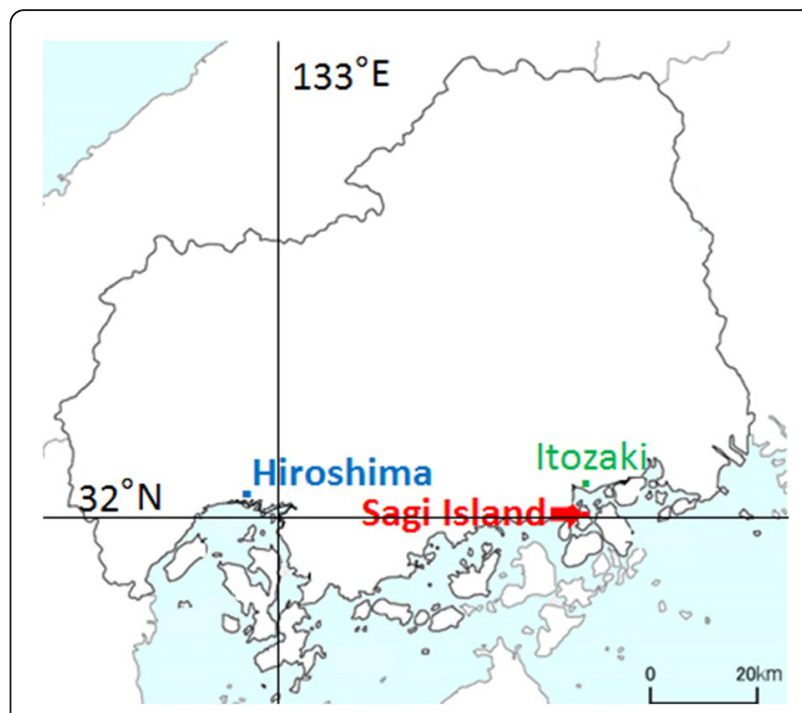

Fig. 2 Locality map of the Sagi Island, Hiroshima, and Itozaki. Sagi Island is located in the Hiroshima Prefecture floating on the Seto Island Sea

of cultural heritage (Ikeuchi et al. 2007; Jordá et al. 2011). Finding a difference between the results of two time measurements of the same target with a certain period leads to detecting the weathering during that period (Gomez-Heras et al. 2008). On the contrary,

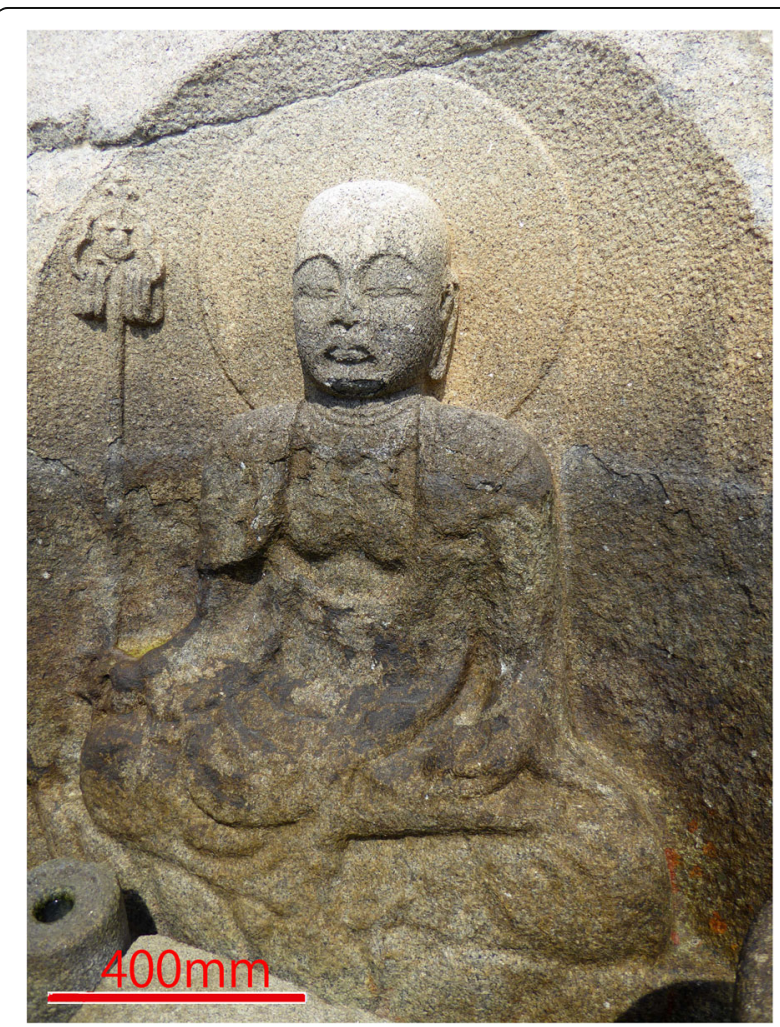

Fig. 3 The present surface condition of the sculpture (2016). The lower part of the sculpture is generally degraded compared with the upper part 


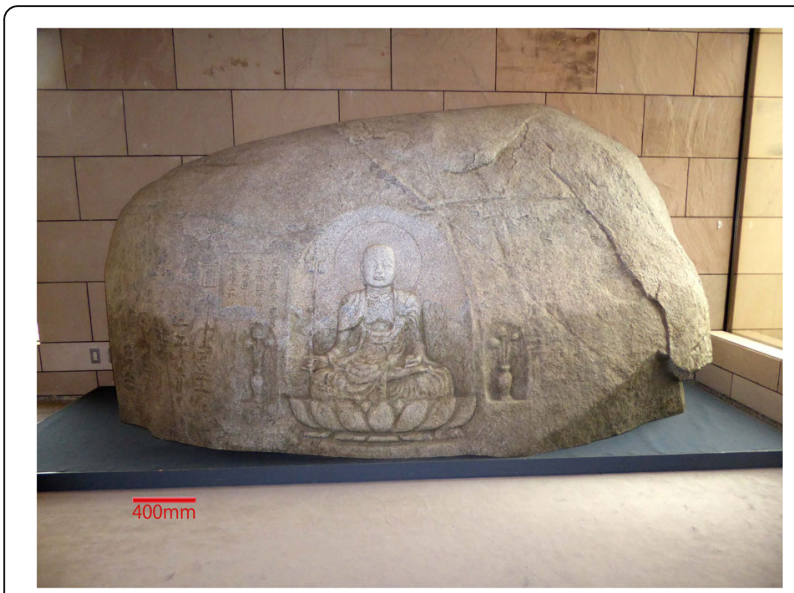

Fig. 4 Replica in the Hiroshima Prefectural History Museum (made in 1986). The replica has continuously been located inside the Museum. The lower mass below the stomach of the sculpture is dark-colored

three-dimensional measurement based on photogrammetry has also been applied to measure cultural heritage because the technique is simple and quick compared with the laser scanning method (Westoby et al. 2012; McCarthy 2014; Fujii et al. 2018). Therefore, it is expected that the degradation speed of cultural heritage may be easily estimated without any special equipment, by measuring the same target twice with an interval using such a method and comparing the data.

However, it is necessary to understand long-term weathering for long-term conservation of cultural heritage. To detect a long-term degradation, an adequate length of interval is required. To solve this problem, it is expected to be effective to measure an old replica of a target made in the past together with the original. If the replica is close enough to the original, the difference can basically be regarded as the progress in the degradation of a target since the replica was made. In this study, the degradation of the Wareishi Rock Cliff Sculpture in the previous 30 years is discussed by comparing it with its replica made 30 years ago.

\section{Wareishi Rock Cliff Sculpture}

The target of this study is the Wareishi Rock Cliff Sculpture (Hiroshima Prefecture 2008) (Fig. 1a), designated as an important cultural property of the Hiroshima Prefecture, in the Sagi Island, Mihara City, Japan (Fig. 2). An inscription besides the sculpture shows that it was carved in A.D. 1300, directly on a core stone (Holmes 1978) of Cretaceous Hiroshima Granitic Rocks, located near a shoreline. No salt efflorescence has ever been reported on the core stone. The sculpture is a bas-relief of an approximately $1 \mathrm{~m}$ tall sitting Buddha. The $\sim 4 \mathrm{~m}$ globular granitic core stone appears above the sea level during low tides (Fig. 1a), whereas a part or all of it sinks below the sea level during high tides (Fig. 1b). The average

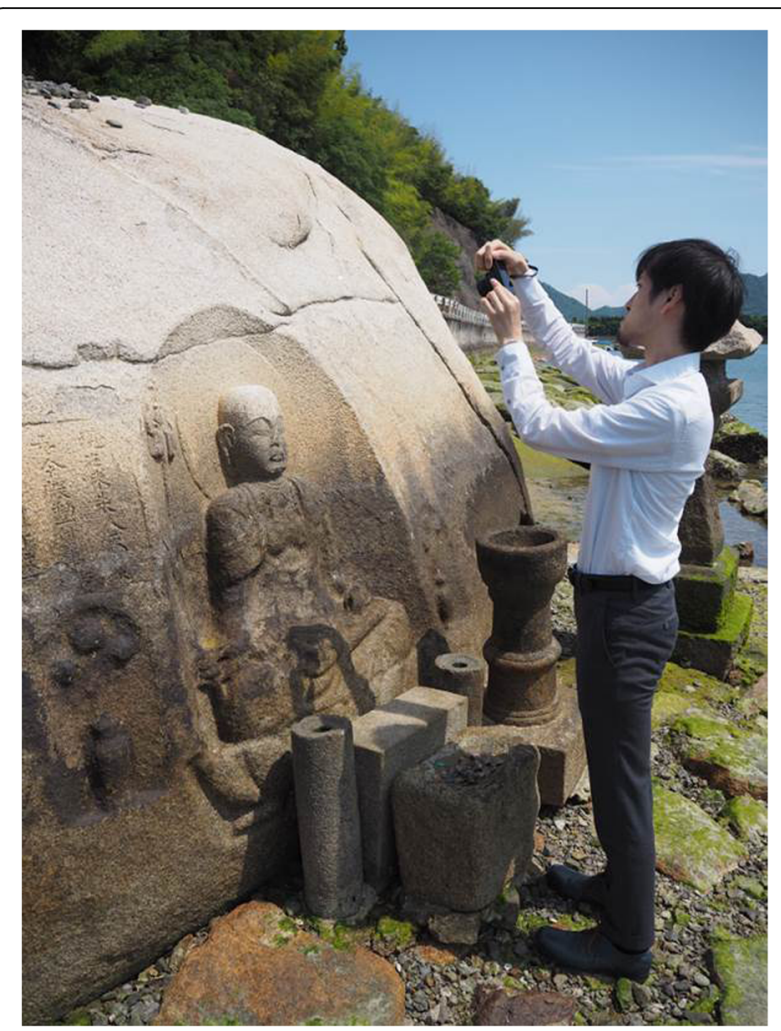

Fig. 5 Photographing the Wareishi Rock Cliff Sculpture. It took approx. 6 min using a compact digital camera basically by one person during low tide. The person is $170 \mathrm{~cm}$ tall

sea level during the high tide of 2016 was estimated to be around the chin or neck of the sculpture based on the tide table in Itozaki (Japan Meteorological Agency 2017), the nearest point of the Meteorological Agency (Fig. 2). The lower mass of the core stone below the chest of the sculpture is covered with dark-colored materials that seem to be algae (Fig. 1a).

About the degradation state of the sculpture, the original surfaces are supposed to be still retained on the upper body, including the face, because of the sharpness of the edges (Fig. 3). On the contrary, the edges of the lower body, including the garment, are not sharp, indicating that the lower part of the sculpture is degraded more than the upper part (Fig. 3). Local people emotionally insist that the degradation of the sculpture is progressing rapidly because of the impact of sea waves; however, this notion does not have any scientific data. Because an investigation must be conducted only during low tide, quantitative data about the sculpture's degradation state have not been obtained to date.

\section{The replica}

There is a replica of the Wareishi Rock Cliff Sculpture made of fiber-reinforced plastics (FRP) in 1986 (Fig. 4), which is located in the Hiroshima Prefectural History 
Museum (Hiroshima Prefectural History Museum 1998). It is said that the replica was made not by imitating with human eyes but by directly copying the sculpture using a mold; first, the mold was formed by using silicon on the original sculpture through thin vinyl sheets, and then, the replica was made with FRP styling in the mold. Because the replica has been conserved inside the Museum since then, the difference between the shapes of the present Wareishi Rock Cliff Sculpture and of the replica can be basically regarded as the degradation during the previous 30 years.

The lower part of the replica is also dark-colored, but the upper boundary of the darkened part is around the stomach of the sculpture (Fig. 4), i.e., lower than that of the present Wareishi Rock Cliff Sculpture, around the chest (Fig. 1a).

\section{Methods/Experimental Photography}

The measurement is required to be carried out easily and quickly because it should be done only during low tide for efficiency. For this reason, multi-view stereo technique based on photogrammetry was used in this study. This technique measures the unevenness of targets not only on particular spots but also on the whole area by taking photographs from various viewpoints (Fig. 5) and matching them. In this study, this technique was applied to detect the planar distribution of displacement. Fifty-seven photographs $(\sim 70 \mathrm{~cm}$ wide each) were taken of the original sculpture, and 43 photographs ( $120 \mathrm{~cm}$ wide) of the replica were taken using a digital camera "PowerShot G7X" from Canon Company. The measurement, conducted in June 2016 by a single person, took $\sim 6 \mathrm{~min}$ for the sculpture and $\sim 4 \mathrm{~min}$ for the replica.

There are several artifacts around the bottom of the original sculpture built in later eras (Fig. 1a), which hamper the observation of the surface of the original sculpture. Therefore, the measured area of the original sculpture was smaller than that of the replica.

\section{Matching}

Three-dimensional coordinates were constructed by the photographs using the multi-view stereo technique by Sakai et al. (2015). First, the positions of the camera center and the optical axis of each photograph were estimated using OpenMVG. Second, by combining more than two photographs of the same spot taken from various viewpoints, partial three-dimensional coordinates were calculated based on the principle of binocular stereopsis. Then, the total three-dimensional coordinates of the Wareishi Rock Cliff Sculpture and of the replica were integrated by compiling the partial three-dimensional data. The three-dimensional

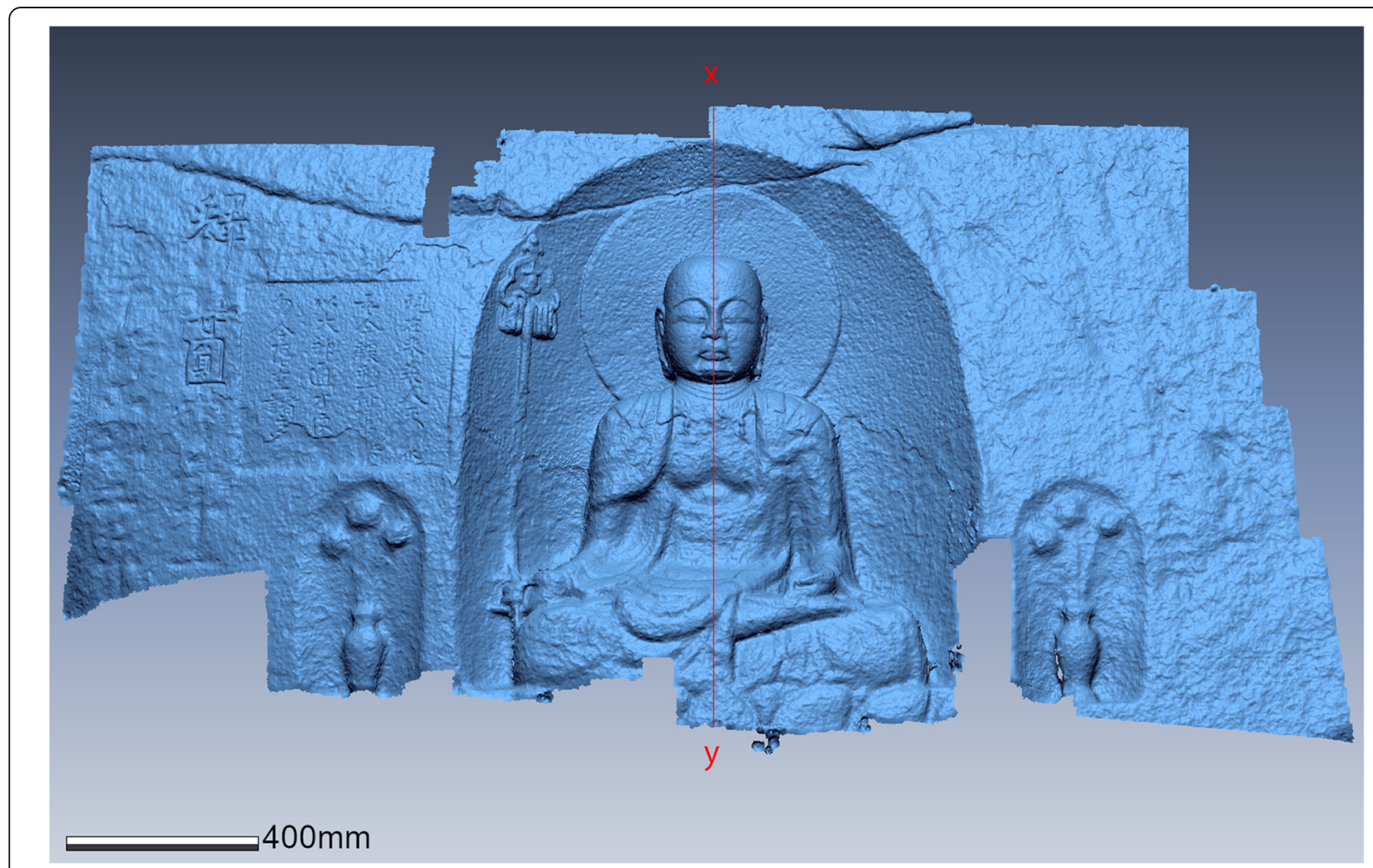

Fig. 6 Orthographic projection of the Wareishi Rock Cliff Sculpture. The $x-y$ line shows the position of the cross section (Fig. 10) 
model of the original sculpture is shown in Fig. 6 and that of the replica in Fig. 7.

\section{Detecting the displacement}

After adjusting each three-dimensional form model, the smallest deviation between the Wareishi Rock Cliff Sculpture (Fig. 6) and the replica (Fig. 7) was calculated by aligning the three-dimensional models through the method of iterative closest point (ICP), minimizing the total deviation of the models (Besl and McKay 1992). The software of Geomagic XOS of the SMARTTECH Company was used in this step. The calculation was carried out on the 31 partial three-dimensional form models (Fig. 8), to avoid impact from broad distortion caused by swelling or shrinkage of FRP. Each partial model area (Fig. 8) was selected to keep the broad distortion smaller than local displacements. Measurement error of this method is theoretically estimated to be less than 0.7 $\mathrm{mm}$ based on former research about multi-view stereo (Sakai 2015). Places where more than $3 \mathrm{~mm}$ of displacement was detected were extracted as the degraded area in the previous 30 years by this study to recognize the difference by naked eyes. The distortion detected within a partial three-dimensional form model (Fig. 8) is always less than $3 \mathrm{~mm}$; thus, the influence of swelling or shrinkage of FRP is negligible.

\section{Results}

The total measured comparable area between the original sculpture and the replica was $2.62 \mathrm{~m}^{2}$. The maximum displacement between the original sculpture and the replica was detected as $9.45 \mathrm{~mm}$ and the mean displacement as $0.878 \mathrm{~mm}$. The areas where more than $3 \mathrm{~mm}$ of difference was detected between the original sculpture and the replica are indicated on the three-dimensional form model of the replica which can be regarded to retain the shape closer to the original shape of the sculpture carved in A.D. 1300 (Fig. 9). The total area where more than $3 \mathrm{~mm}$ of difference is observed is $0.0148 \mathrm{~m}^{2}$, which corresponds to $\sim 0.56 \%$ of the whole measured area.

The difference between the shapes of the original sculpture and the replica was detected mainly on the middle part of the core stone constituting a horizontal belt $\sim 20 \mathrm{~cm}$ parallel to the sea surface (Fig. 9). The upper surface of the belt where displacement concentrates concurs with the upper surface of the

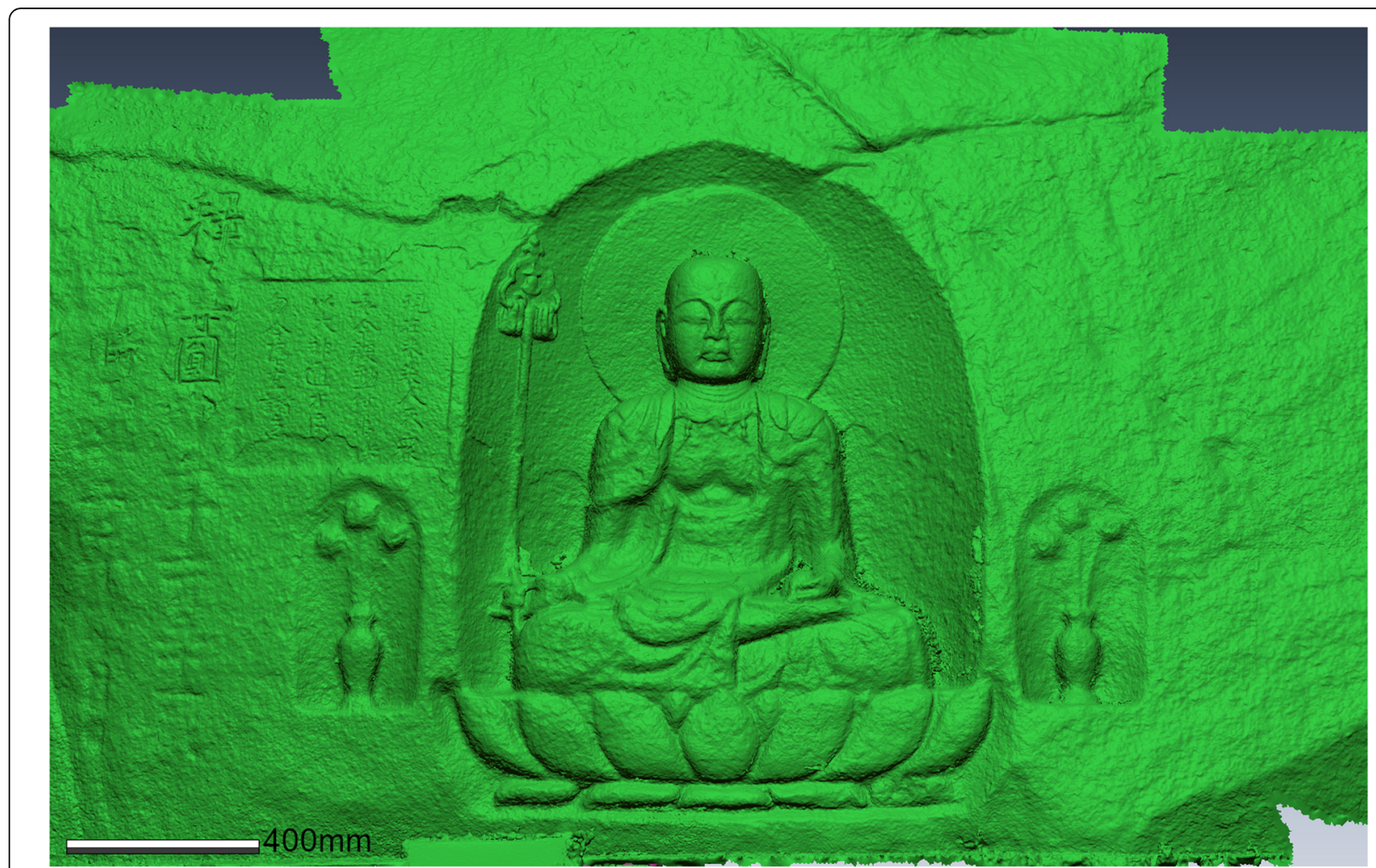

Fig. 7 Orthographic projection of the replica 


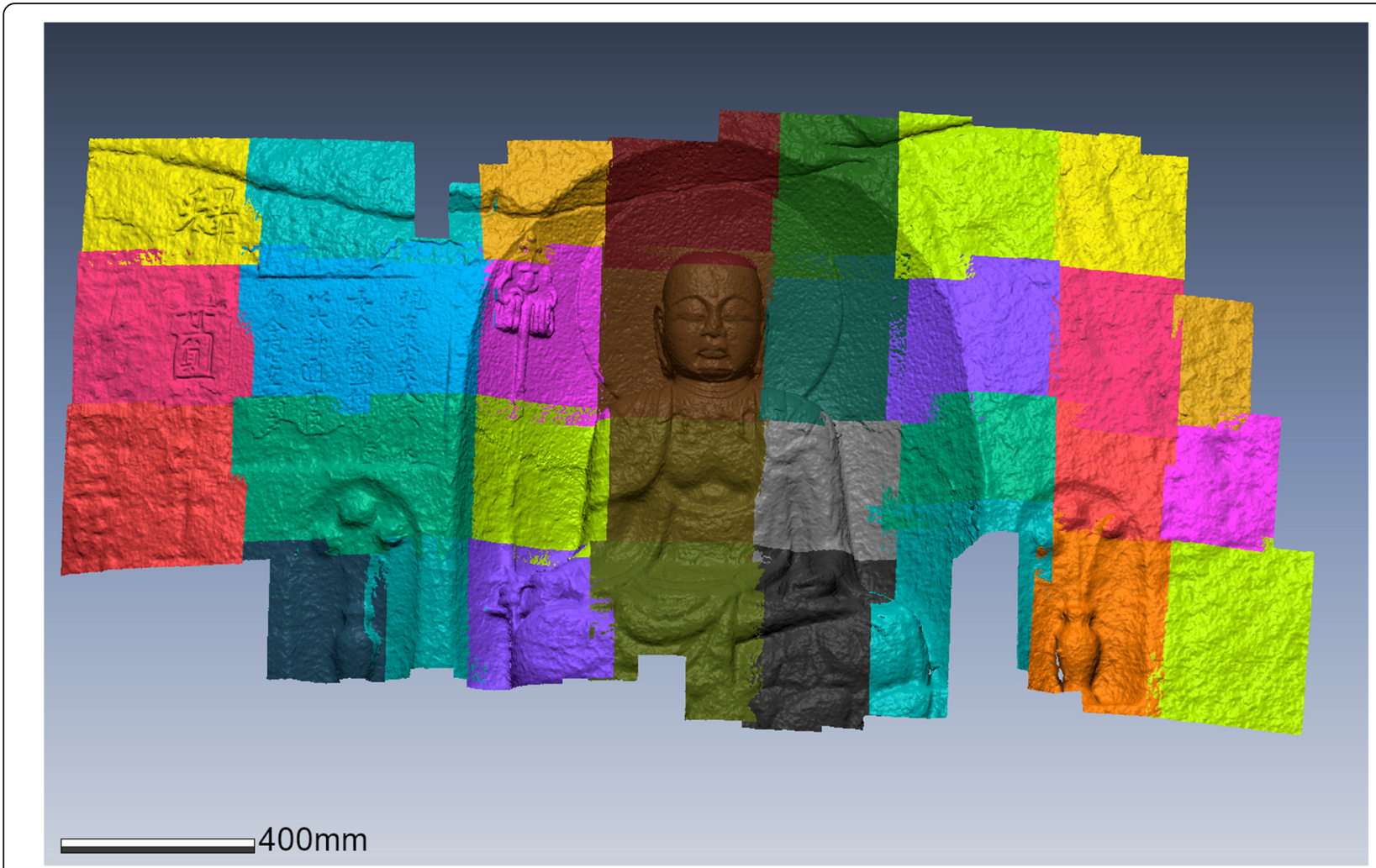

Fig. 8 Positions of the partial three-dimensional form models where the difference between the original sculpture and the replica was calculated. Each partial model area was selected to keep the broad distortion smaller than local displacements, free from swelling or shrinkage of FRP

dark-colored area of the original sculpture (Figs. 1a and 9), and the lower limit of the belt concurs with the upper surface of the dark-colored area of the replica (Figs. 4 and 9).

\section{Discussion}

The present shape of the core stone is nearly globular without extreme encroachments (up to several centimeters in depth: Fig. 1a). If weathering of the core stone was severe, some geomorphological features should be detected. The area where the displacement was detected between the original sculpture and the replica does not cover a wide range (only $\sim 0.56 \%$ ), indicating that the current detectable degradation of the Wareishi Rock Cliff Sculpture has occurred only in limited areas.

The detected displacement areas are scattered mainly within the belt-shaped area where dark colorization has progressed in the previous 30 years. The dark-colored area, the upper line of which concurs with the average seawater surface during high tide, is considered to relate to the supply of the seawater during high tide (Fig. 10). Then, it is possible that the rise in sea level in the previous 30 years has resulted in the degradation during that period. In fact, the average sea level in Hiroshima, the nearest spot where the continuous sea level data of these 30 years are available (Fig. 2), has risen up to $20 \mathrm{~cm}$ (Geospatial Information Authority of Japan 2018), and there are no significant active faults between Sagi Island and Hiroshima. In other words, the average sea level during high tide may be related to the degradation of the sculpture physically and/or chemically. Because the lower part of the sculpture has not retained the original surface (Fig. 3), it can be concluded that the degradation of the Wareishi Rock Cliff Sculpture has not been proceeding only recently but continuously since being carved.

If the degradation speed is fixed, the total degradation can be calculated based on the displacement of the previous 30 years, $\sim 0.56 \%$ in the whole measurement area $(0.56 \% / 30$ years $\times 716$ years $=13.4 \%)$; a total degradation of $13.4 \%$ occurred after being carved. The past degradation is assumed to have progressed mainly in the lower part of the sculpture, because the average sea level during A.D. 1300 has been estimated to be much lower than the present level based on the studies of local climatological change in Japan (Tange 


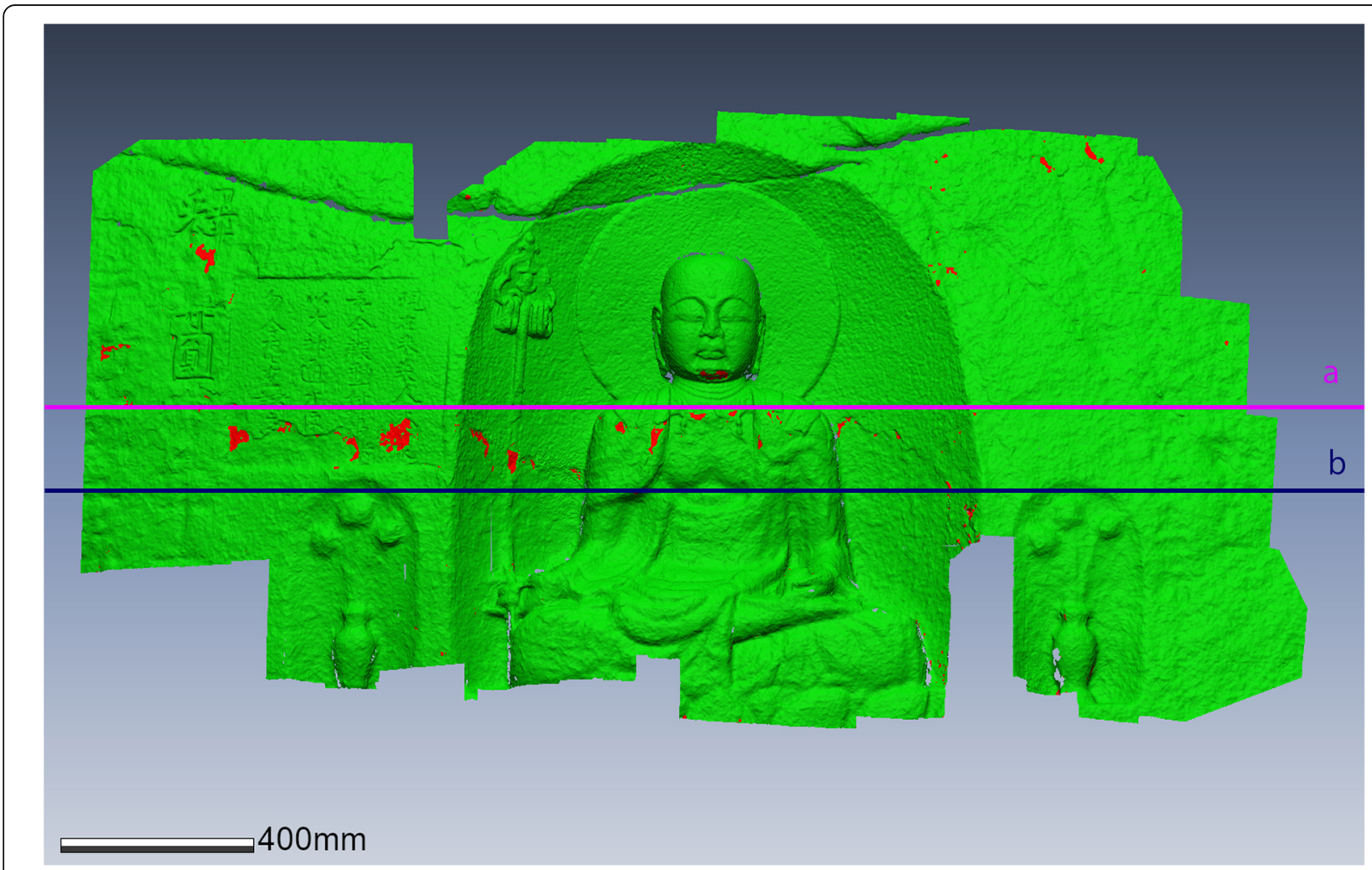

Fig. 9 Displacement map between the Wareishi Rock Cliff Sculpture and the replica. Ortho-image facing to the replica. Red represents more than $3 \mathrm{~mm}$ of the detected displacement, and green represents less than $3 \mathrm{~mm}$ of the detected displacement. a (pink line): The upper line of the present alga lushness area. b (blue line): The upper line of the alga lushness area in 1986 (Lines "a" and "b" were drawn by the same person based on the naked eye observation.)

2013). The original surface seems to be mainly lost by more than $13.4 \%$ on the lower part of the present sculpture, indicating that the previous degradation was not considerably smaller than the recent degradation. Consequently, it is not considered that the Wareishi Rock Cliff Sculpture has recently been suffering from increasing amount of rapid degradation during the previous 30 years. The present condition is more likely to be caused by the historically continuous degradation.

However, if the sea level rises further, it is possible that the upper essential part of the sculpture will be subjected to degradation, i.e., the face. In such a scenario, some countermeasures may be required. Conservation measures must be discussed by considering the process to remove the degradation causes rather than strengthening the object. Because the degradation area basically concurs with the average sea level during high tide, floating materials such as driftwood are considered to be one of the causes of degradation. In addition, some barriers in front of the sculpture may become an effective measure against further degradation by such causes than consolidation of the sculpture with synthetic resins. Thus, not subjective but prudent and objective consideration is required for the conservation of cultural heritage.

\section{Conclusions}

The degradation state of the Wareishi Rock Cliff Sculpture, an important cultural property of Hiroshima Prefecture, was discussed based on the three-dimensional measurement using multi-view stereo of the present sculpture and the replica made in 1986. The area where more than $3 \mathrm{~mm}$ of displacement was observed constituted $\sim 0.56 \%$ of the whole measured area, and the area was distributed in a 20 $\mathrm{cm}$ high belt-shaped portion parallel to the sea surface, indicating a possibility that the rise in sea level during the previous 30 years may have influenced this partial degradation. Therefore, some countermeasures, such as building barriers in front of the sculpture, may be required if the degradation extends to the face of the sculpture in the future.

In this study, 30-year degradation of the target monument has been revealed; further, the conservation policy has been proposed based on the measurement of the original and the replica at the same time. Because the method is relatively simple and quick, it 


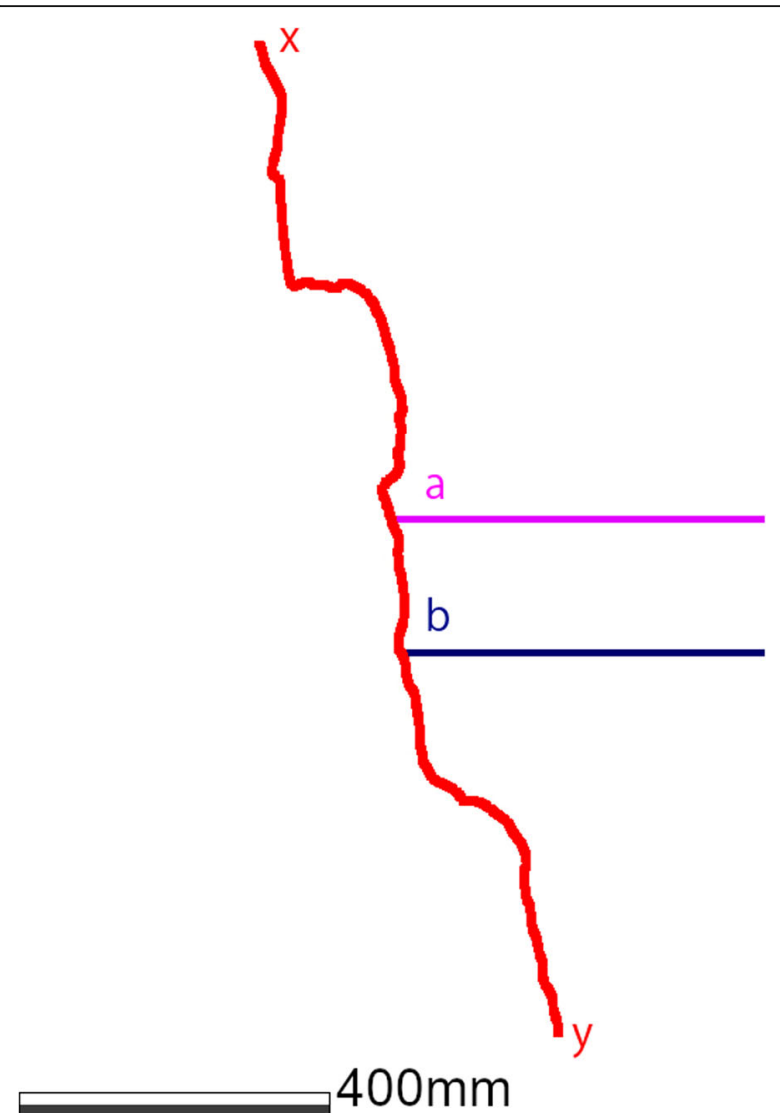

Fig. 10 Cross section of the Wareishi Rock Cliff Sculpture. The positions of " $x$ " and " $y$ " are shown in Fig. 6. a (pink line): The upper line of the present alga lushness area probably represents the present average sea level during high tide. $\mathbf{b}$ (blue line): The upper line of the alga lushness area in 1986 probably represents the average sea level during high tide in 1986

will contribute to the conservation of other cultural heritages. Moreover, replicas are sometimes made for geological characteristic outcrops, such as faults, unconformities, folds, and fossil containing outcrops. In such a case, this method will contribute to the discussion of the weathering rate of various rocks based on the displacement during a long period.

\section{Acknowledgements}

The measurement of the Wareishi Rock Cliff Sculpture was performed through the support of Mr. Hideyuki Matsuda from the Mihara City; he also provided permission for the publication of this result. The measurement of the replica was executed in the presence of Mr. Tomohiro Yamamoto of the Hiroshima Prefectural History Museum who also obtained the permission for the publication of the result. The authors express their sincere gratitude to them.

\section{Funding}

This work was supported by the "Research on the degradation factors of outdoor monuments and their conservation measures" funded by the Tokyo National Research Institute for Cultural Properties.

\section{Availability of data and materials}

The data of this study are available from the corresponding author on reasonable request.

\section{Authors' contributions}

NK proposed the topic and conceived and designed the study. MM promoted the cooperation with coauthors and owners of the targets. SS and $\mathrm{HU}$ clicked photographs and calculated the three-dimensional coordinates. All the authors have read and approved the final manuscript

\section{Competing interests}

The authors declare that they have no competing interests.

\section{Publisher's Note}

Springer Nature remains neutral with regard to jurisdictional claims in published maps and institutional affiliations.

\section{Author details}

${ }^{1}$ Tokyo National Research Institute for Cultural Properties, 13-43 Ueno Park, Taito-ku, Tokyo 110-8713, Japan. ${ }^{2}$ Toppan Printing Co., Ltd, 1-3-3 Suido, Bunkyo-ku, Tokyo 112-8531, Japan.

Received: 30 March 2018 Accepted: 15 January 2019

Published online: 04 February 2019

\section{References}

Besl PJ, McKay ND (1992) A method for registration of 3-D shapes. IEEE Trans Pattern Analysis and Machine Intelligence 14:239-256. https://doi.org/10. $1109 / 34.121791$

Doehne E, Price CA (2010) Stone conservation: an overview of current (second edition). The Getty Conservation Institute, Los Angels

Fujii Y, Shogaki T, Miyakawa M (2018) Photogrammetric documentation and noninvasive investigation of a stone dry dock, the Yokosuka Arsenal dry dock No. 1, Japan. Eng Geol 234:122-131. https://doi.org/10.1016/j.enggeo.2017.12.022

Geospatial Information Authority of Japan (2018) http://cais.gsi.go.jp/cmdc/ center/kentyoujo/hirosima/hirosima.html Accessed 17 Dec 2018

Gomez-Heras M, Smith BJ, Viles HA, Meneely J, McCabe S (2008) HD laser scanning for the evaluation of salt decay laboratory simulations of building limestone, Proceedings of the salt weathering on buildings and stone sculptures (SWBSS 2008). Technical University of Denmark, Copenhagen, pp 149-158

Hiroshima Prefectural History Museum (1998) http://www.mars.dti.ne.jp/ suzukiy/hiroreki_e.html Accessed 17 Dec 2018

Hiroshima Prefecture (2008) http://www.hiroshima-bunka.jp/english/detail/057. html Accessed 17 Dec 2018

Holmes A (1978) Holms principles of physical geology, 3rd edn. Wiley; Indian Forester, Hoboken

Ikeuchi K, Oishi T, Takamatsu J, Sagawa R, Nakazawa A, Kurazume R, Nishino K, Kamakura M, Okamoto Y (2007) The Great Buddha Project: digitally archiving, restoring, and analyzing cultural heritage objects. Int J Comput Vis 75: 189208. doi.org/10.1007/s11263-007-0039-y

Japan Consortium for International Cooperation in Cultural Heritage (2013) Japan's International Cooperation in Heritage Conservation http://www.jcic-heritage.jp/ wp-content/uploads/2015/04/2013 eng.pdf Accessed 17 Dec 2018

Japan Meteorological Agency (2017) http://www.data.jma.go.jp/gmd/kaiyou/db/ tide/suisan/suisan.php?stn=|Z Accessed 17 Dec 2018

Jordá F, Navarro S, Pérez A, Cachero R, López D, Lerma JL (2011) Close range photogrammetry and terrestrial laser scanning: high resolution texturized $3 \mathrm{D}$ model of the Chapel of the Kings in the Palencia Cathedral as a case study. In: Pavelka K (ed) Proceedings of the XXIIIrd international CIPA symposium, CTU-CIPA, Prague, 2011

McCarthy J (2014) Multi-image photogrammetry as a practical tool for cultural heritage survey and community engagement. J Archaeol Sci 43:175-185. https://doi.org/10.1016/j.jas.2014.01.010

Moses C, Robinson D, Barlow J (2014) Methods for measuring rock surface weathering and erosion: a critical review. Earth Sci Rev 135:141-161. https:// doi.org/10.1016/j.earscirev.2014.04.006

Sakai S (2015) Research on the multi-view three-dimensional restoration based on highly precise window agreement. Dissertation, University of Tohoku

Sakai S, Ito K, AOKI T, Watanabe T, Unten H (2015) Phase-based window matching with geometric correction for multi-view stereo. IEICE T Inf Syst E98-D:1818-1828 doi.org/10.1587/transinf.2014EDP7409 
Smith BJ, Prïkryl R (2007) Diagnosing decay: the value of medical analogy in understanding the weathering of building stones. Geol Soc Lond, Spec Publ 271:1-8. https://doi.org/10.1144/GSL.SP.2007.271.01.01

Stephenson WJ, Finlayson BL (2009) Measuring erosion with the micro-erosion meter-contributions to understanding landform evolution. Earth Sci Rev 95: 53-62 doi.org/10.1016/.jearscirev.2009.03.006

Szmelter I (2013) New values of cultural heritage and the need for a new paradigm regarding its care, conservation: cultures and connections. https:// journals.openedition.org/ceroart/3647 Accessed 17 Dec 2018

Tange $Y$ (2013) Japanese history deciphered by climatology -1400 years fighting with abnormal weathers-, Nikkei publishing Inc. ISBN-10: 4532168805 (in Japanese)

UNESCO World Heritage Centre (2005) Basic Texts of the 1972 World Heritage Convention. http://whc.unesco.org/uploads/activities/documents/activity562-4.pdf. Accessed 8 Apr 2018

Westoby MJ, Brasington J, Glasser NF, Hambrey MJ, Reynolds JM (2012) 'Structure-from-Motion' photogrammetry: a low-cost, effective tool for geoscience applications. Geomorphology 179:300-314. https://doi.org/10. 1016/j.geomorph.2012.08.021

Winkler EM (1986) The measurement of weathering rates of stone structures: a geologist's view. APT Bulletin: The Journal of Preservation Technology 18:65-70

\section{Submit your manuscript to a SpringerOpen ${ }^{\circ}$ journal and benefit from:}

- Convenient online submission

- Rigorous peer review

- Open access: articles freely available online

High visibility within the field

- Retaining the copyright to your article

Submit your next manuscript at $\boldsymbol{\nabla}$ springeropen.com 